\title{
Limits of Oxygen Enrichment, Tuyere Fuel Injection, and Prospect of Stack Gas Injection in an Experimental Furnace*
}

\author{
By Tsuneo MIYASHITA, ${ }^{* *}$ Hiroaki NISHIO, ${ }^{* *}$ Teruo SHIMOTSUMA, ,* \\ Takeo YAMADA, ${ }^{* *}$ and Mitsuru OHTSUKI***
}

\begin{abstract}
Synopsis
The phenomena taking place in applying oxygen enrichment to blast furnaces were studied by using an experimental furnace $\left(0.63 \mathrm{~m}^{3}\right) . A$ slight decrease in the coke rate was obtained at the ratio less than $4 \%$ oxygen enrichment, but beyond this rate, it increased by more than 2.5 $\mathrm{kg} / \mathrm{tHM}$ for every $1 \%$ of enrichment due to the increase in direct reduction. Beyond the ratio of $9 \%$ oxygen enrichment. the temperature of the thermal reserve zone decreased up to $15 \%$. Although an appropriate amount of fuel injection through normal tuyeres improves this condition, there existed a possible operation range restricted by the upper limit of the heat content ratio, a lower limit of the theoretical flame temperature, and a lower limit of the excess oxygen ratio. The limit of tuyere fuel injection, even with more than $4 \%$ of oxygen enrichment, was estimated to be about $110 \mathrm{~kg} / \mathrm{tHM}$ of fuel oil.

Reformed gas was produced by partial combustion of oil with oxygen injected into the stack of an enlarged experimental furnace $\left(3.2 \mathrm{~m}^{3}\right)$. The coke rate was decreased from 570 to $361 \mathrm{~kg} / \mathrm{tHM}$ by injecting $628 \mathrm{Nm}^{3} / \mathrm{tHM}$ of gas. This decrease was proved to come from the increase in gaseous reduction of $20 \%$, the sensible heat of the injected gas, and the decrease in heat loss. The stack gas injection of $512 \mathrm{Nm}^{3} / \mathrm{tHM}$ together with $7 \%$ of oxygen enrichment prevented the retardation of the heat exchange caused by oxygen enrichment and achieved a high productivity without any increase in the coke rate.
\end{abstract}

\section{Introduction}

Tuyere fuel injection with oxygen enrichment has become economical in Japan due to the recent rise in the price of coking coal. Studies so far made on the effect of oxygen enrichment are the theoretical research conducted by J. Michard ${ }^{1)}$ and experiments carried out in experimental furnaces of $\mathrm{CRM}^{21}$ and of the U.S. Bureau of Mines. ${ }^{3)}$ According to the previous reports, ${ }^{4,5)}$ it should be noted that the limit of tuyere injection would be about $110 \mathrm{~kg} / \mathrm{tHM}$ of auxiliary fuel even with more than $4 \%$ of oxygen enrichment.

Fuel injection beyond this limit was achieved by injecting the reformed gas into the furnace stack. The aim of this technique is to reduce the ore burden by the cheap reformed gas produced from various hydrocarbons in the shaft of the blast furnace; the minimum amount of coke that can be saved would amount to approximately $200 \mathrm{~kg} / \mathrm{tHM}^{\left.6,{ }^{6}{ }^{23}\right)}$ In the blast furnace, the inevitable difficulties in a shaft furnace such as the formation of cluster and ununiform reduction of ores can be avoided by small amounts of coke acting in the form of inert material as the reducing agent. Experimental operation with reformed gas injection has already been tested in Pompey, ${ }^{7}$ the U.S. Bureau of Mines, ${ }^{8)}$ Nippon Steel, ${ }^{9)}$ and CRM ${ }^{10)}$ but it is still in the development stage.

\section{Experimental Procedures ${ }^{11)}$}

An original experimental furnace (Fig. 1) of two pebble stoves, heating the air up to $1100^{\circ} \mathrm{C}$ and with an automatic conveyor charging system capable of 2000 charges per day, was built in 1967. In 1969 , the furnace was enlarged to six time as large as its original scale (Fig. 1) and heavy insulation was adopted to keep the heat loss level on a par with that of a commercial furnace. Thus the enlarged furnace can be operated at about $550 \mathrm{~kg} / \mathrm{tHM}$ of coke rate with $100 \%$ of self fluxed sinter.

\section{Phenomena of Oxygen Enrichment and Its Limit}

The effect of oxygen enrichment for increasing production is a well-known fact, but there are two opposite results ${ }^{12,13)}$ reported for the coke rate. In order to explain quantitatively the phenomena of the influence of oxygen enrichment and its limit, the ex-

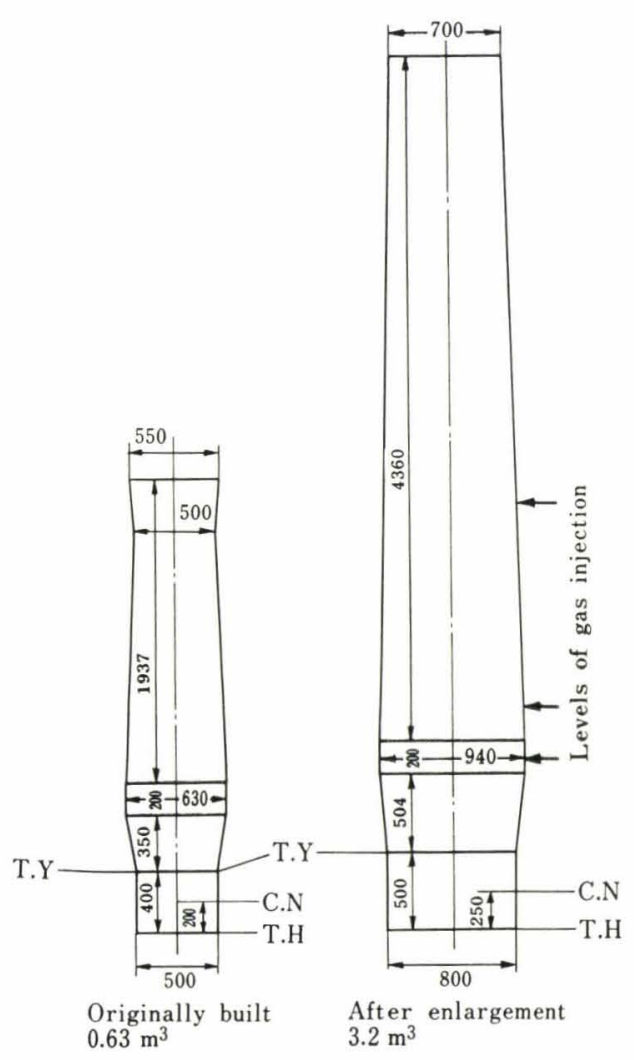

Fig. 1. Experimental furnaces (originally built and enlarged)

\footnotetext{
* Received March 22, 1972.

** Technical Research Center, Nippon Kokan K.K., Minamiwatarida-cho, Kawasaki-ku, Kawasaki 210

*** Fukuyama Works, Nippon Kokan K.K., Kokan-cho, Fukuyama 720.
} 
periments have been made by using the gas of $19 \%$ oxygen enriched for a constant bosh gas volume in the original experimental furnace.

\section{The Effect of Oxygen Enrichment on the Coke Rate}

From the results ${ }^{11,14}$ ) obtained in the original furnace, shown in Fig. 2, the coke rate decreased slightly at the range of oxygen content less than $25 \%$, but beyond that, an increase of more than $2.5 \mathrm{~kg} / \mathrm{tHM}$ for every $1 \%$ oxygen enrichment was encountered due mainly to the increase in the loss of the solution carbon. As shown in Fig. 3, a relatively large decrease in the heat loss at the refining zone resulted in a saving in coke at the content of $25 \%$ oxygen, but in the latter range, the increase in direct reduction was higher. At the content of $36 \%$ oxygen, the shaft efficiency became greater owing to the decrease in the amount of reducing agent, but in the case of direct reduction, it became smaller and the amount of oxygen removed increased.

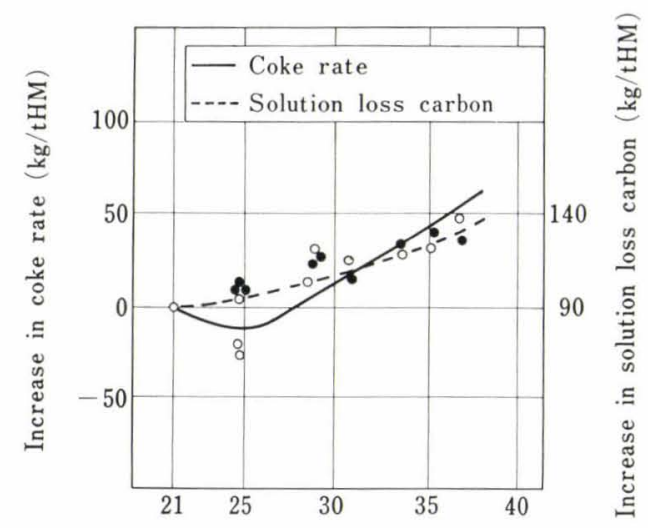

Oxygen content in hot blast (\%)

Fig. 2. Increase in the coke rate and the solution loss carbon according to the oxygen enrichment

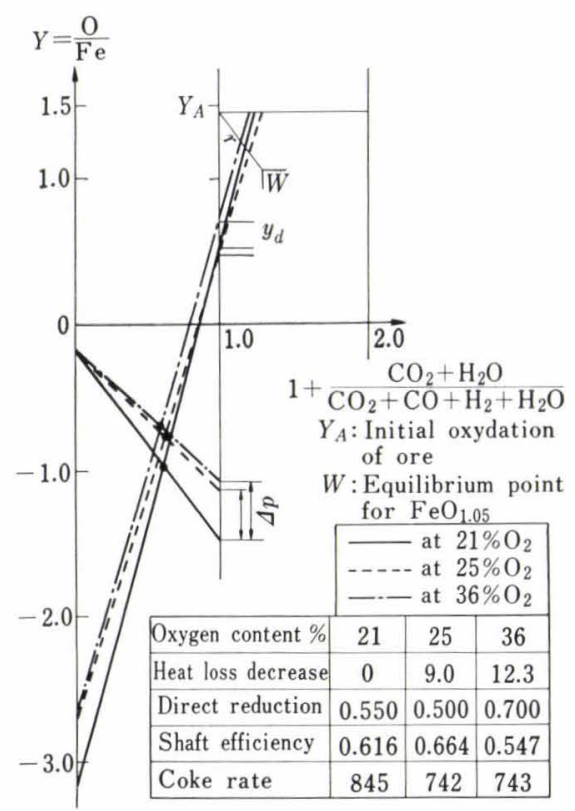

Fig. 3. Decreases of heat loss $(\Delta p)$, direct reduction $\left(y_{d}\right)$, and shaft efficiency $(r)$, according to the different oxygen enriched ratio
2. The Limit of Oxygen Enrichment due to the Retardation of the Heat Exchange in the Shaft

As shown in Fig. 4, the gas temperature in the shaft dropped at an oxygen content of more than $30 \%$, and the thermal reserve zone, tended to vanish at the content more than $36 \%$ oxygen. These reproducible results ${ }^{14)}$ were obtained in the enlarged experimental furnace.

The heat transfer equations ${ }^{14)}$ for the counter current packed bed can be applied to the blast furnace shaft, assuming the plug flow of gas and solids and the overall transfer coefficient to be $2000\left(\mathrm{kcal} / \mathrm{bed} \cdot \mathrm{m}^{3}\right.$. $\mathrm{deg} \cdot \mathrm{hr}$ ) as constant, while ignoring ununiformity of gas and solid distributions in the radial direction.

The heat content ratio defined by Eq. (1) is the most important factor.

$$
u=m c / G k
$$

where,

$k, c:$ specific heat of the gas and solids ( $\mathrm{kcal} / \mathrm{kg}$. $\operatorname{deg})$

$G, m$ : mass flow rate of the gas and solids $(\mathrm{kg} / \mathrm{hr})$.

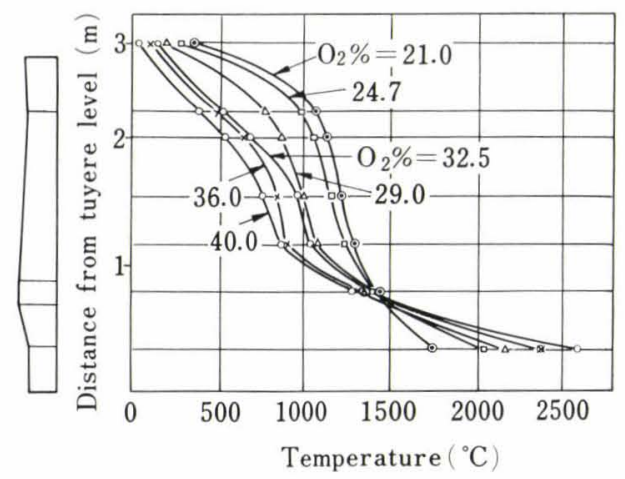

Fig. 4. Effect of oxygen enrichment on the gas temperature profile

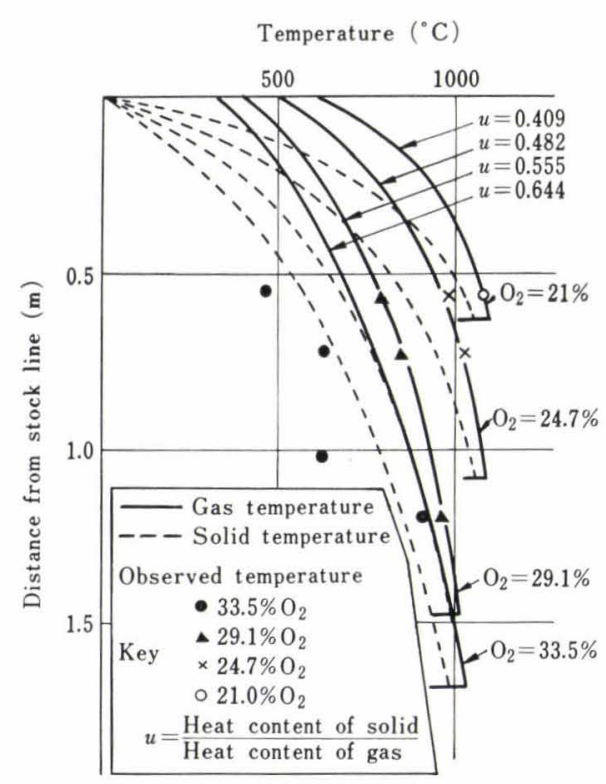

Fig. 5. Effect of oxygen enrichment on the length of thermal reserve zone and on $u$ from calculated and observed results 


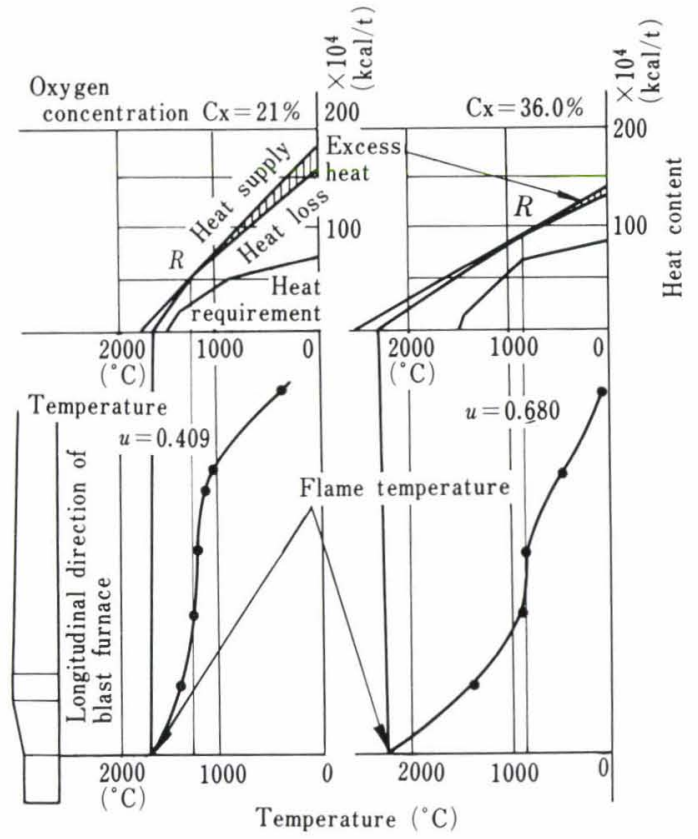

Fig. 6. Staged heat balances and observed temperature profiles at 0 and $15 \%$ oxygen enrichment

Average heat content $m c$ can be calculated by applying the figures of specific heat, $0.22(\mathrm{kcal} / \mathrm{kg} \cdot \mathrm{deg})^{15)}$ for the coke and $0.20(\mathrm{kcal} / \mathrm{kg} \cdot \mathrm{deg})^{15)}$ for the ore.

where,

$$
m c=0.22 \cdot m_{\text {coke }}+0.20 \cdot m_{\text {ore }}
$$

$m_{\text {coke }}, m_{\text {ore }}$ : mass flow rates of coke and ore.

The calculated gas and solid temperatures for the different oxygen enrichments are shown in Fig. 5. Thus the theory ${ }^{14}$ ) stated that depending on the increase of the oxygen enrichment, the lengths of the thermal reserve zone become shorter and that the temperature of the gas and solids in the preparation zone are lowered, was proved to be correct.

The heat content ratio, $u$, is an important factor that the heat exchange at the shaft increases to 0.75 , which was close to the limit of the heat exchange in the original furnace. This limit can easily be explained from the staged heat balances ${ }^{16)}$ calculated for the standard period and the content of $36 \%$ oxygen which corresponds to the gas temperature profiles as shown in Fig. 6, where the critical point $R$ at the least heat margin moved to the upper shaft and the excess heat decreased.

\section{Direct Reduction Increase due to the Temperature Profile Changes}

Since the gas film resistance is almost negligible in furnace stacks, the ore reduction rate along the furnace height was calculated by putting the gas temperatures and compositions in Eq. (3) (Fig. 7):

$$
\begin{aligned}
R_{\mathrm{CO}}= & \frac{3}{d_{o} r_{o}} \\
& \cdot \frac{\left(C_{\mathrm{CO}}-C_{\mathrm{CO}}^{\mathrm{eq}}\right)}{\frac{r_{o}}{D} \cdot \frac{1-(1-F)^{1 / 3}}{(1-F)^{1 / 3}}+k_{\mathrm{CO}}(1-F)^{2 / 3}\left(1+1 / K_{\mathrm{CO}}\right)}
\end{aligned}
$$

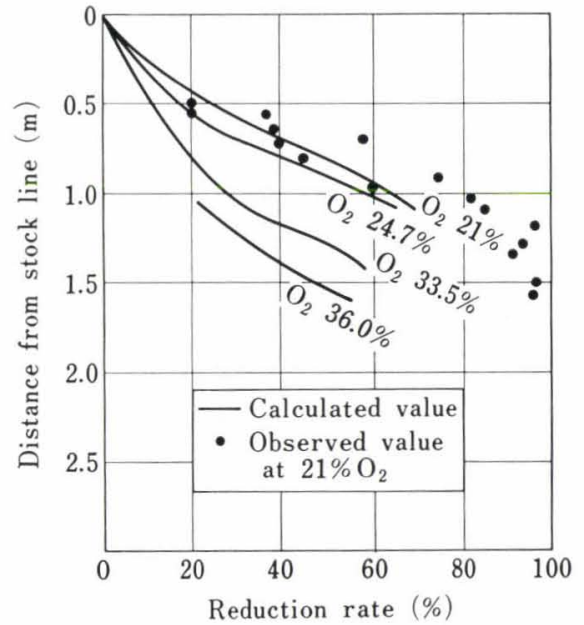

Fig. 7. Effect of oxygen enrichment on the progress of iron ore reduction in the furnace shaft

where,

$F:$ reduction rate of ore $(-)$

$r_{o}:$ initial ore size $(\mathrm{cm})$

$d_{o}$ : specific oxygen concentration, $6.66 \times 10^{-2}$ $\left(\mathrm{mol} / \mathrm{cm}^{3}\right)$

$C_{\mathrm{CO}}, C_{\mathrm{co}}^{\mathrm{eq}}$ : concentration of $\mathrm{CO}$ in the bulk and concentration of $\mathrm{CO}$ equilibrated to wüstite at $1000^{\circ} \mathrm{C}\left(\mathrm{mol} / \mathrm{cm}^{3}\right)$

$K_{\mathrm{CO}}$ : equilibrium constant of $\mathrm{CO}$ and wüstite

$D$ : diffusion coefficient $\left(\mathrm{cm}^{2} / \mathrm{sec}\right)$

$k_{\mathrm{CO}}$ : rate coefficient of $\mathrm{CO}$ reduction.

The terms of $D$ and $k_{\mathrm{CO}}$ were experimentally obtained from the reduction of the same kind of sinter in $\mathrm{CO}$ $\mathrm{CO}_{2}-\mathrm{N}_{2}$ gas at $800^{\circ}$ to $1000^{\circ} \mathrm{C}$ which was used in the experimental operation. Thus, the activation energy was $8.35 \mathrm{kcal} / \mathrm{mol}$ and the value of $D$ was 2.49 $\mathrm{cm}^{2} / \mathrm{sec}$

$$
k_{\mathrm{co}}{ }^{14)}=40.4 \exp (-4200 / T) .
$$

As the result calculated from Eq. (3), at the content of $36 \%$ oxygen, more than $45 \%$ of unreduced iron oxide descended into the lower shaft $1.6 \mathrm{~m}$ under the stock line and was reduced by direct reduction. As the ratio of oxygen enrichment increased, the amount of reduction decreased and the residual iron oxide was finally reduced by direct reduction in the lower part of the furnace. Investigations ${ }^{17}$ ) revealed that after nitrogen quenching the reduction rate of ore reached more than $95 \%$ (plotted points) in this area at the content of $21 \% \mathrm{O}_{2}$, at which point the burden started to melt. A large amount of descent of the unheated and unreduced burden according to the retardation of heat exchange would affect the metallurgical reaction in the crucible. Thus, another limit of oxygen enrichment in a blast furnace is clearly possible in the reduction process of ore.

\section{The Limit of the Fuel Injection through Normal Tuyeres with Oxygen Enrichment}

Advantages of oxygen enrichment are mentioned as follows : 
(1) Productivity can be increased without increasing the gas flow rate.

(2) Flame temperature which is important in injecting auxiliary fuel can be maintained at a constant temperature.

(3) Combustion rate can be improved due to high oxygen potential.

Some disadvantages of oxygen enrichment, as derived from the description in Chapter III, are as follows:

(4) The retardation of heat transfer at the upper shaft.

(5) An increase in direct reduction at the lower shaft.

The necessary conditions for injecting a large amount of fuel through normal tuyeres are as follows:

(A) Heat must be supplimented to compensate for the heat dissociation and preheating of the fuel.

(B) Prevention of soot formation when the fuel burns at tuyeres.

However some advantages from fuel injection may be expected.

(C) An increase in the gas amount as $\mathrm{H}_{2}$ produced by the combustion of the fuel.

(D) An increase in the amount of reducing agent such as $\mathrm{H}_{2}$ and the ability to promote the reduction at low temperatures.

Among the items mentioned above, (2) and (A), (3) and (B), (4) and (C), and (5) and (D) are mutually compensated when a large amount of fuel is injected together with an appropriate amount of oxygen enrichment. However, certain limits exist in the fuel injection through a normal tuyere even with oxygen enrichment on account of the following limitations.

\section{The Limits of the Flame Temperature and the Heat Content Ratio}

The limit for the heat content ratio was considered to be about $0.82^{18)}$ in a commercial furnace, which was investigated for comparison ${ }^{5)}$ in modern furnace operations. It is clear from Fig. 6 that the heat content ratio becomes greater as a result of decreasing excess heat below $1000^{\circ} \mathrm{C}$ due to the decrease in gas volume $\left(\mathrm{Nm}^{3} / \mathrm{tHM}\right)$ when the flame temperature was raised while keeping the coke rate constant. From this fact, the upper limit of the flame temperature is closely correlated to the limit of the heat content ratio. The lower limit of the flame temperature which is important to maintain the necessary reaction temperature is determined in the correlation of the heat balance at the refining zone.

\section{The Limit from the Excess Oxygen Ratio}

Combustion of the oil particles atomized at the tuyeres progresses in the following stages: heat increase in oil particles; the evaporation and combustion of volatile matter; the rise in heat of residual carbon particles and the combustion. The time required for the first and third stages are very short, therefore, the last stage governs the whole reaction. According to Essenhigh, ${ }^{19)}$ assuming that the combustion mechanism of fine particles is obeyed to diffusion control, the mass transfer coefficient can be given as $D / a$
(D, $a$ : the diffusion coefficient and the diameter of particle), thus this is obeyed to the square law. The combustion progress of oil particles can be calculated if the five assumptions listed below are adopted.

(1) The above three stage-stage reactions continue until the oil particles arrive at the end of tuyere nose.

(2) Residual carbon particles and raceway coke are consumed by the following three reactions. Their reaction rates are controlled by the gas film diffusion of $\mathrm{O}_{2}, \mathrm{CO}_{2}$, and $\mathrm{H}_{2} \mathrm{O}$.

$$
\begin{aligned}
& \mathrm{C}+\mathrm{O}_{2}=\mathrm{CO}_{2} \\
& \mathrm{C}+\mathrm{CO}_{2}=2 \mathrm{CO} \\
& \mathrm{C}+\mathrm{H}_{2} \mathrm{O}=\mathrm{CO}+\mathrm{H}_{2}
\end{aligned}
$$

(3) Gas compositions generated in raceway are controlled by the combustion of raceway coke.

(4) Variation of gas amount in raceway can be ignored.

(5) Mass transfer coefficients of $\mathrm{O}_{2}, \mathrm{CO}_{2}$, and $\mathrm{H}_{2} \mathrm{O}$ are considered to be equal.

Compositions of gas and the burning oil particle diameter at any point along the distance 1 from tuyere nozzle can be calculated by the following fundamental equations.

$\begin{array}{ll}\text { For } \mathrm{O}_{2}, & G\left(d x_{1} / d l\right)=-a_{p}\left(k_{f} P / R T\right) \ldots \ldots \\ \text { For } \mathrm{CO}_{2}, & G\left(d x_{2} / d l\right)=a_{p}\left(k_{f} P / R T\right)\left(x_{1}-x_{2}\right) . \\ \text { For } \mathrm{H}_{2} \mathrm{O}, & G\left(d x_{3} / d l\right)=-a_{p}\left(k_{f} P / R T\right) x_{3} \ldots\end{array}$

For the residual carbon burnt oil particle,

$$
d a \mid d l=-\left(M_{c} / \sigma\right)(D P / a R T)(\varepsilon P / R T)\left(x_{1}+x_{2}+x_{3}\right) \ldots
$$

where,

$$
\begin{aligned}
& x_{1}, x_{2}, x_{3} \text { : mole fractions of } \mathrm{O}_{2}, \mathrm{CO}_{2} \text {, and } \mathrm{H}_{2} \mathrm{O} \\
& (-) \\
& a \text { : radius of residual carbon burnt oil } \\
& \text { particle }(m) \\
& l \text { : distance from tuyere nose }(\mathrm{m}) \\
& a_{p}, \varepsilon: \quad \text { specific surface of raceway coke }\left(\mathrm{m}^{2} / \mathrm{m}^{3}\right) \\
& \text { and void fraction }(-) \\
& k_{f}, D \text { : mass transfer coefficients of } \mathrm{O}_{2}, \mathrm{CO}_{2} \text {, }
\end{aligned}
$$

Initial conditions can be adopted at tuyere nose based on the above assumptions as follows:

$$
\begin{aligned}
& x_{1}=x_{10}, x_{2}=x_{20}, x_{3}=x_{30}, \text { and } a=a_{0} \text { at } l=0 \text { (tuyere } \\
& \text { noze) }
\end{aligned}
$$

Thus, Eqs. (5), (6), (7), and (8) can be solved to obtain Eq. (9). 


$$
\begin{aligned}
a_{o}{ }^{2}-a^{2}= & \left(k_{s} / 4 k_{c}\right)\left\{\left(2 x_{10}+x_{20}+x_{30}\right)\right. \\
& \left.-\left(x_{10} k_{c} l+x_{20}+x_{30}\right) \exp \left(-k_{c} l\right)\right\}
\end{aligned}
$$

where,

$$
k_{c}=a_{p}\left(k_{f} / G R T\right) \text { and } k_{s}=8\left(M_{c} / \sigma\right)(D P / R T)
$$
$(\varepsilon P / R T)$.

$k_{c}, k_{s}$ : rate of combustion of raceway coke and residual carbon burnt oil particle.

A critical burnt oil particle having no soot formation can be calculated by Eq. (9) if ' $a$ ' approaches to ' 0 ' when ' $l$ ' approaches to $\infty$.

$$
a_{o}=\sqrt{ }\left(k_{s} / 4 k_{c}\right)\left(2 x_{10}+x_{20}+x_{30}\right)
$$

In the laboratory scale experiments a relationship of $\left(2 a_{o} / d_{d}\right)^{3}=0.20$ was obtained for the fraction of the residual carbon in oil. The critical oil particle which forms soot $d_{d}(\mathrm{~m})$ can be calculated by substituting this into Eq. (10).

$$
d_{d}=1.7 \sqrt{\left(k_{s} / k_{c}\right)\left(2 x_{10}+x_{20}+x_{30}\right)} .
$$

Figure 8 shows the effect of the oxygen enrichment ratio on the critical excess oxygen ratio (total amount of oxygen entering through tuyeres/necessary amount of oxygen for the complete combustion of oil, 2.2 $\mathrm{Nm}^{3} / \mathrm{kg}$ oil) calculated by Eq. (11). Almost all of the recent results from commercial furnaces fall within this calculated line. In Fig. 9, these data were plotted according to the relationship between oil rate and oxygen enrichment. The theoretical limit was assumed to be $36 \mu$ in critical oil particle, which is sufficiently small in ordinary atomization and well explains the possible oil rate with oxygen enrichment.

Without oxygen enrichment, the maximum amount of tuyere oil injection is considered to be about 60 $\mathrm{kg} / \mathrm{tHM}$. For the case of $4 \%$ oxygen enrichment, the maximum limit will reach $110 \mathrm{~kg} / \mathrm{tHM}$ at the

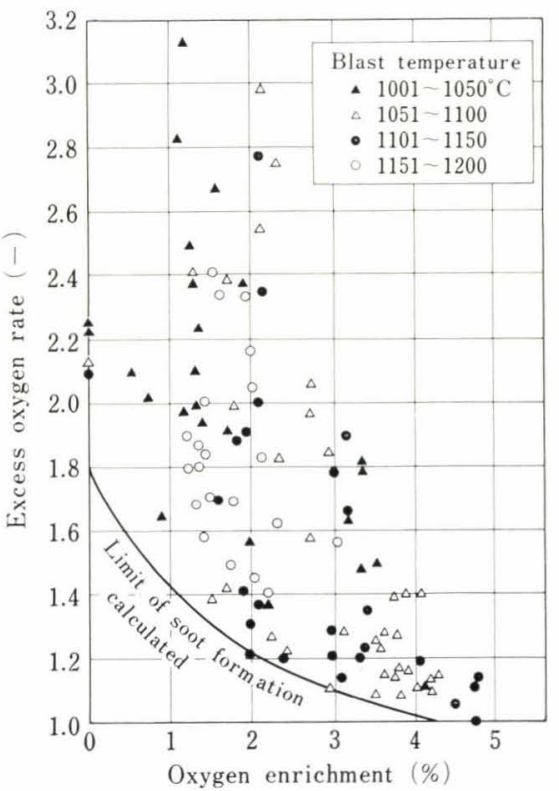

Fig. 8. Relationship between excess oxygen ratio and oxygen enrichment for tuyere oil injection with slight soot formation excess oxygen ratio 1.0, even though the oxygen enrichment ratio is further increased, as shown in Fig. 8. Therefore, oxygen enrichment up to $3 \%$ greatly effects the increase in the limit. If the total amount of oxygen through tuyeres decreases, this maximum limit would be less than $110 \mathrm{~kg} / \mathrm{tHM}$.

\section{The Limit of the Tuyere Fuel Injection with Oxygen Enrichment}

If it is assumed that the limit of heat content ratio is 0.8 , and if the limit of excess oxygen ratio is given in Fig. 8, the possible operating area in the oil injection with oxygen enrichment is given in Fig. 9. Almost all the recent data from commercial furnaces fall within this area. This area is represented by the polyhedron shown in Fig. 10, calculated for different

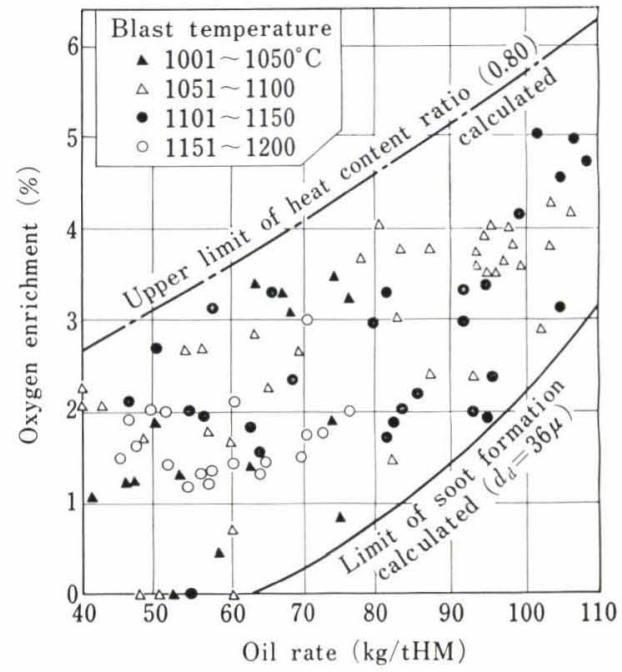

Fig. 9. Possible operational ranges with tuyere oil injection together with oxygen enrichment

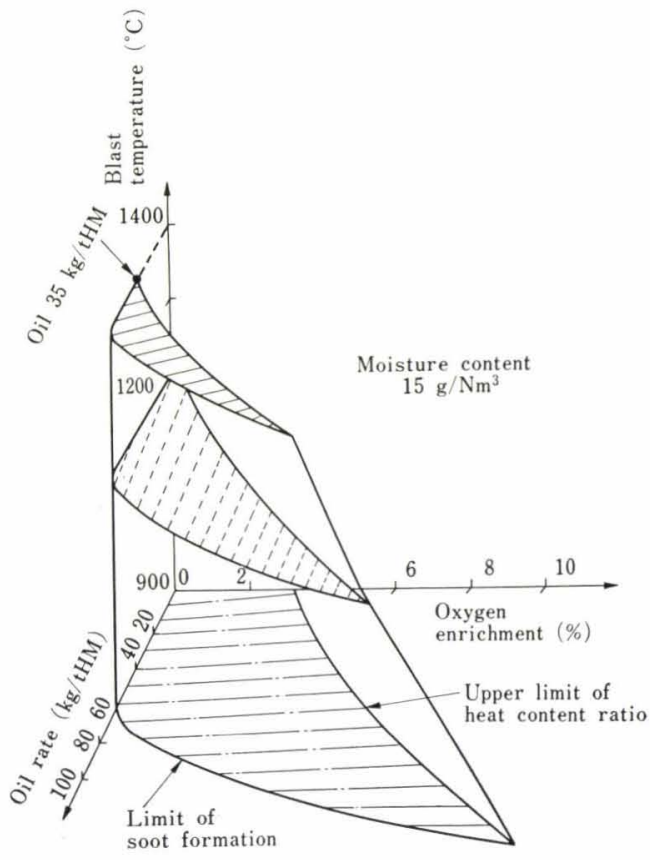

Fig. 10. Possible operational ranges at different oil rate oxygen enrichment and blast temperature 
blast temperatures, oil rates and oxygen enrichment ratios at a constant humidity. When the blast temperature rises, the possible operation range is found to be narrower. Below $35 \mathrm{~kg} / \mathrm{tHM}$ of oil, it cannot be injected without additional steam at $1400^{\circ} \mathrm{C}$, since it exceeds the limit of heat content ratio.

\section{Reformed Gas Injection into the Enlarged Experimental Furnace Stack}

1. The Effect of the Amount of Injected Gas on the Coke Rate

The reformed gas injection was tested in the enlarged experimental furnace ${ }^{20)}$ and its operating results are shown in Table 1. The coke rate decreased from about $570 \mathrm{~kg} / \mathrm{tHM}$ for the standard period to $361 \mathrm{~kg} / \mathrm{tHM}$ as the minimum when $628 \mathrm{Nm}^{3} / \mathrm{tHM}$ of reformed gas was injected and the production increased by about $7.5 \%$ for every $100 \mathrm{Nm}^{3} / \mathrm{tHM}$ of the gas injected from the corrected data of wind leakage. Table 1 shows the results of the reformed gas injection with constant wind rate, the gas injection through a nozzle of $1.5 \mathrm{~m}$ above the normal injected level, and the appropriate gas injection with the oxygen enrichment keeping the bosh gas volume constant. Reformed gas was produced by the partial combustion of oil with oxygen. The gas contained about $4 \%$ of soot for oil carbon and was injected at the temperatures of $1200^{\circ}$ to $1300^{\circ} \mathrm{C}$.
Experimental results were plotted in Fig. 11 which shows the relationship between the oil equivalent rate and the coke rate and the replacement ratio. The dotted line shows the corrections of the factors such as the sensible heat of the injected gas, temperature and

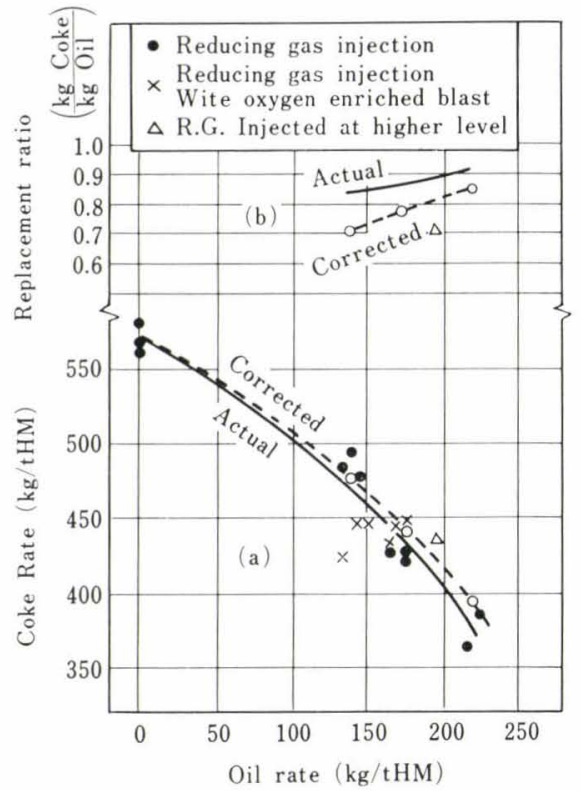

Fig. 11. Effect of the reducing gas on the coke rate (a) and the replacement ratio (b)

Table 1. Results of stack gas injection in the enlarged furnace

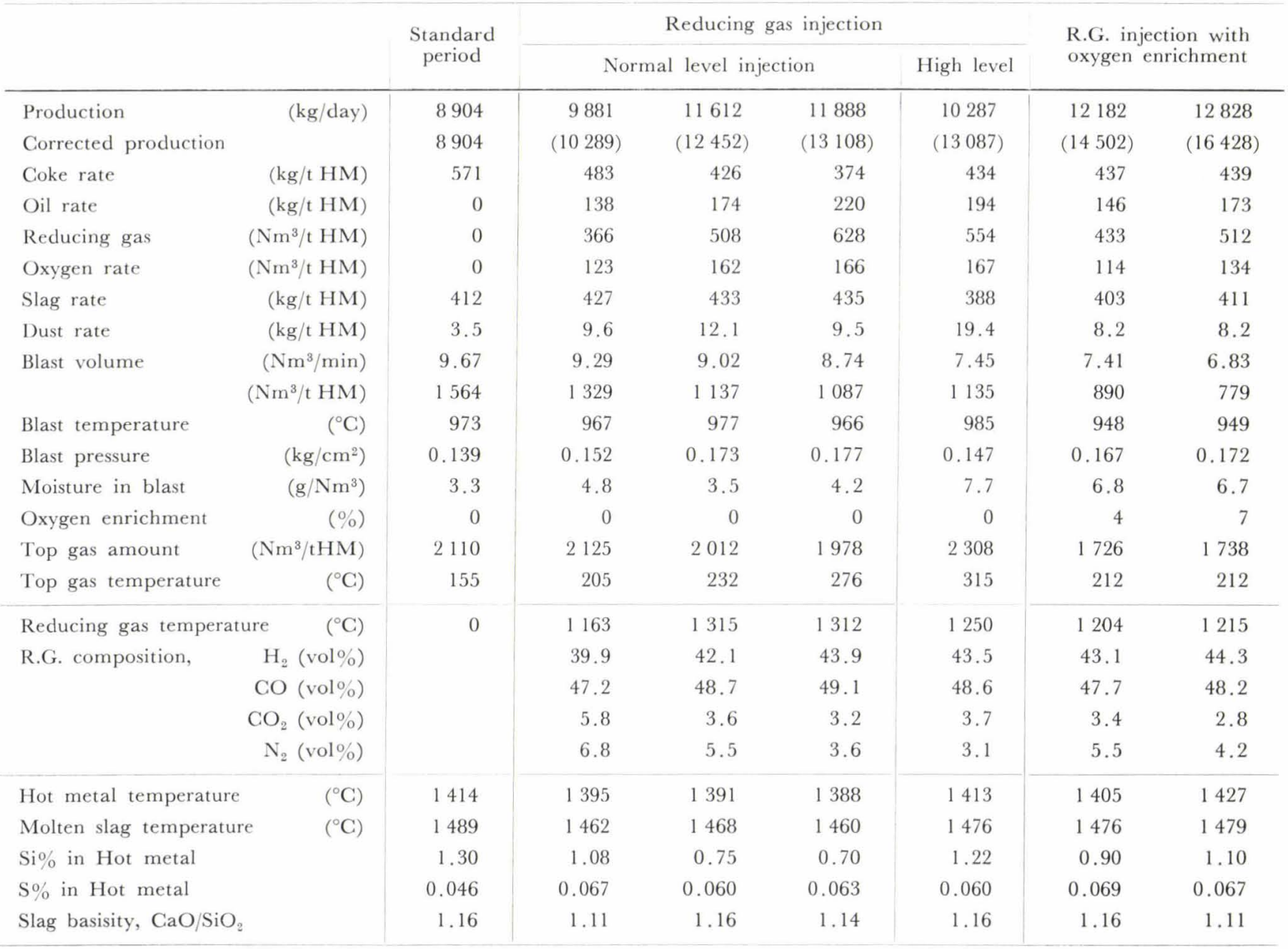


composition of the hot metal and slag based on a heat balance above $1000^{\circ} \mathrm{C}$ level. The replacement ratio changed from 0.75 to 0.82 . The coke rate in the case of gas injection with oxygen enrichment decreased along the same line obtained from the gas injection only. But in the case of injection from a $1.5 \mathrm{~m}$ higher position, the replacement ratio decreased about 0.1 and less effect was obtained.

\section{The Progress in the Reduction Reaction in the Furnace}

The following facts were obtained from the material balance (Table 2.)

(1) Gas injection rate increased when the total amount of gas $\left(\mathrm{Nm}^{3} / \mathrm{tHM}\right)$ was kept almost constant, but the blast volume decreased.

(2) Total amount of $\left(\mathrm{CO}+\mathrm{H}_{2}\right)$ increased.

(3) Gas utilization was about $40 \%$ for $\mathrm{CO}$ and 35 to $40 \%$ for $\mathrm{H}_{2}$ in the normal level injection but they decreased in the injection at $1.5 \mathrm{~m}$ higher level.

(4) Amount of oxygen removed by direct reduction decreased from 0.21 in $\mathrm{O}$ atom $/ \mathrm{Fe}$ atom.

(5) Shaft efficiency ${ }^{21)}$ was almost constant at 0.80 to 0.83 but decreased to 0.78 in the case of $1.5 \mathrm{~m}$ higher level injection.

As shown in Fig. 12, when the amount of injected gas increased, the decrease in direct reduction was replaced by the increased in $\mathrm{H}_{2}$ reduction. However, the calculation was made by assuming that water gas reaction reached equilibrium at $600^{\circ} \mathrm{C}$, and that some parts of the hematite and magnetite were reduced to wüstite by hydrogen. It may be right to say that the reduction by $\left(\mathrm{CO}+\mathrm{H}_{2}\right)$ gas increased from 65 to $85 \%$ by the reformed gas injection.

The results for the standard period (solid line) and for $628 \mathrm{Nm}^{3} / \mathrm{tHM}$ of reformed gas injection (dotted line) are shown as operating lines in Fig. 13, according to the reformed gas injection equilibrium point $W$ moved to $W^{\prime}$ due to the effect of $\mathrm{H}_{2}$, although the amount of the oxygen removed by direct reduction decreased from $Y_{D}$ to $Y_{D^{\prime}}^{\prime}$ total moles of reducing agent per $\mathrm{Fe}$ atom increased due to the decrease in direct reduction. But a decrease in the coke rate proportional to the decrease in the gradient was obtained. Parts of $\mathrm{CO}_{2}$ and $\mathrm{H}_{2} \mathrm{O}$ inevitably contained in the gas will consume by coke as shown in the effect of $Y_{G D}$ qualitatively. Therefore, the reformed gas must contain as little $\mathrm{CO}_{2}$ and $\mathrm{H}_{2} \mathrm{O}$ as possible and its price must be cheaper because of the increase in the total moles of the reducing agents.

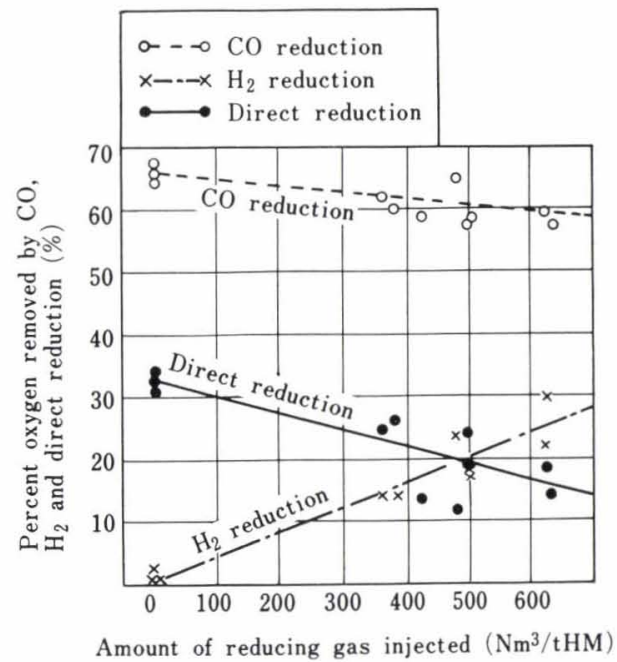

Fig. 12. Effect of reducing gas on the reduction process

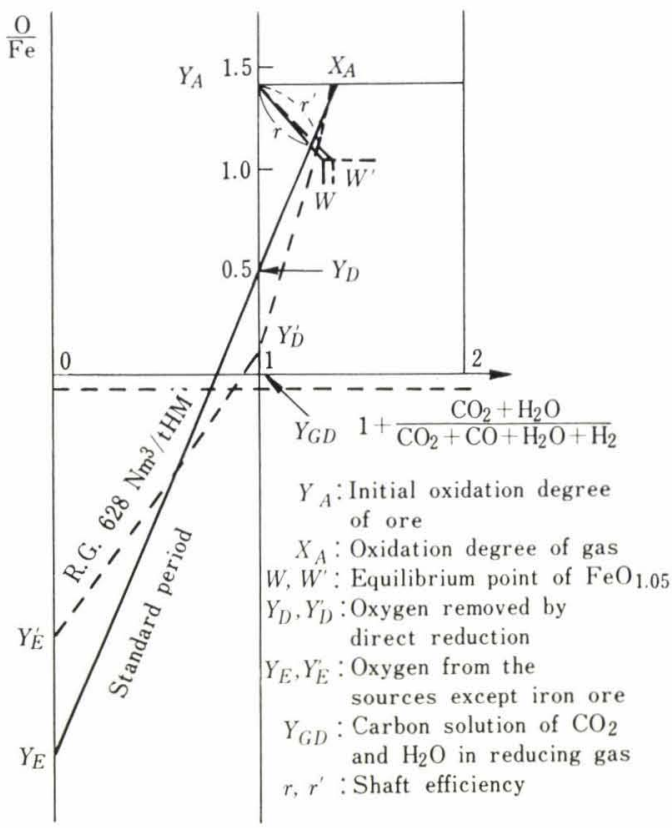

Fig. 13. Operating lines of standard period and reducing gas injection

Table 2. Material balances

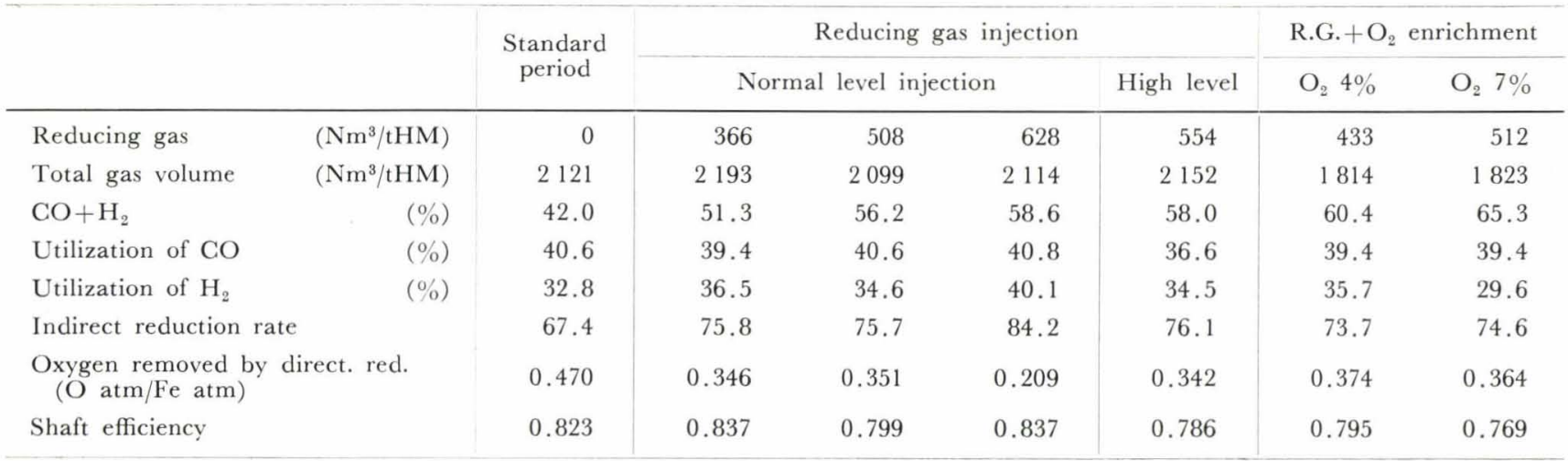


The distributions of reduction along the furnace height were calculated from the observed temperatures and compositions according to Eqs. (3) for $\mathrm{CO}$ reduction and (12) for $\mathrm{H}_{2}$ reduction. For $\mathrm{H}_{2}$ reduction, only the chemical reaction control was assumed, since the resistances of diffusion of $\mathrm{H}_{2}$ through gas film and within reacted core are smaller than that of the chemical reaction.

$$
R_{\mathrm{H}_{2}}=\left(3 / d_{o} r_{o}\right) \cdot k_{\mathrm{H}_{2}}(1-F)^{2 / 3}\left(1+1 / K_{\mathrm{H}_{2}}\right)\left(C_{\mathrm{H}_{2}}-C_{\mathrm{H}_{2}}^{\mathrm{eq}}\right) \ldots
$$

$K_{\mathrm{H}_{2}}$ : equilibrium constant of $\mathrm{H}_{2}$ and wüstite at $1000^{\circ} \mathrm{C}$

$C_{\mathrm{H}_{2}}, C_{\mathrm{H}_{2}}^{\mathrm{eq}}$ : concentrations of $\mathrm{H}_{2}$ in the bulk gas and at the equilibrium to wüstite at $1000^{\circ} \mathrm{C}\left(\mathrm{mol} / \mathrm{cm}^{3}\right)$

The velocity of $\mathrm{H}_{2}$ reduction was obtained from the reduction test of the same kind of ore used in the test operation as follows:

$$
k_{\mathrm{H}_{2}}{ }^{20)}=181.3 \exp (-6158 / T)
$$

Assuming that the additive property of $\mathrm{H}_{2}$ reduction and $\mathrm{CO}$ reduction is correct, the progress of the reduction can be calculated by Eq. (14) for the mixed gas reduction.

$$
d F / d \theta=R_{\mathrm{CO}}+R_{\mathrm{H}_{2}}
$$

The reduction rate calculated by Eq. (14) in relation to the dimensionless retention time is shown in Fig. 14. Ore reduced in the same retention time increased by two times, with $628 \mathrm{Nm}^{3} / \mathrm{tHM}$ of gas injection. The calculated reduction rate agreed with the observed rates ${ }^{17)}$ in the study of the quenched furnace.

\section{Considerations from the Heat Balances}

The staged heat balance calculations ${ }^{16)}$ made by assuming that $\mathrm{H}_{2}$ reduction takes place between $400^{\circ}$ and $900^{\circ} \mathrm{C}$ for gas injection period at $628 \mathrm{Nm}^{3} / \mathrm{tHM}$ are shown in Fig. 15. In this figure, it shows that the heat supply (a dot-dash-line) generated from the burning of coke crosses necessary heat at about $950^{\circ} \mathrm{C}$

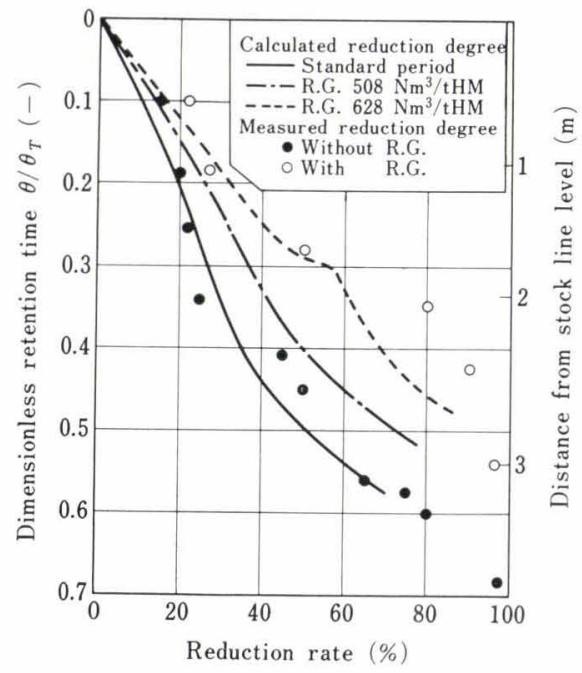

Fig. 14. Reduction progress with and without reducing gas injection to the dimensionless retention time (dotted line) when gas is injected. However, this heat shortage was covered by the sensible heat of the injected gas. From this fact, a reformed gas injection will be effective if it is injected the lower shaft where the temperature is higher than $950^{\circ} \mathrm{C}$. The temperature should be higher than that of the injected zone, otherwise, the sensible heat of the injected gas will be exhausted, necessitating an increase in top gas temperature or additional coke to bring up the gas heat.

The heat balances calculated above $1000^{\circ} \mathrm{C}$ (Fig. 16) are convenient to investigate the contribution of the reformed gas injection on a blast furnace heat requirement. In the period of the gas injection only,

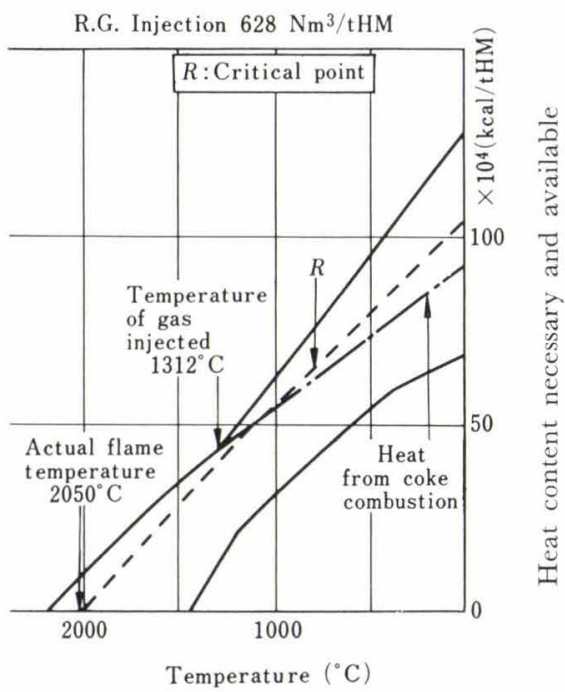

Fig. 15. Staged heat balances with or without reducing gas injection

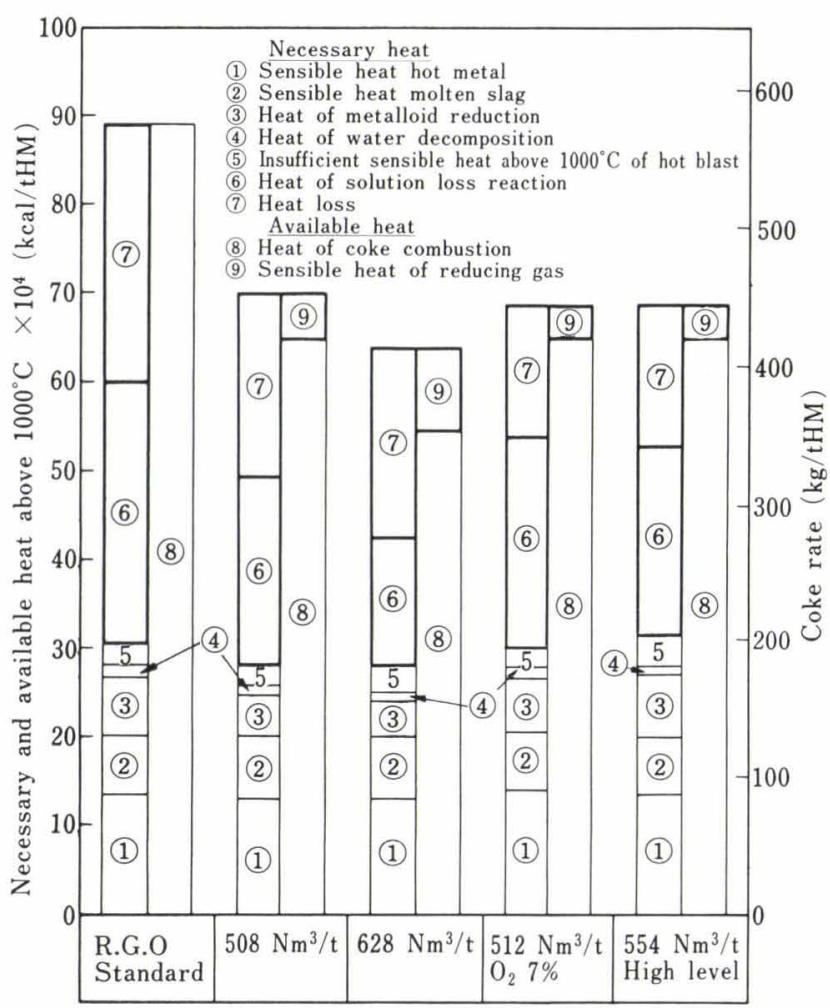

Fig. 16. Heat balances at $1000^{\circ} \mathrm{C}$ standard for tested operation 


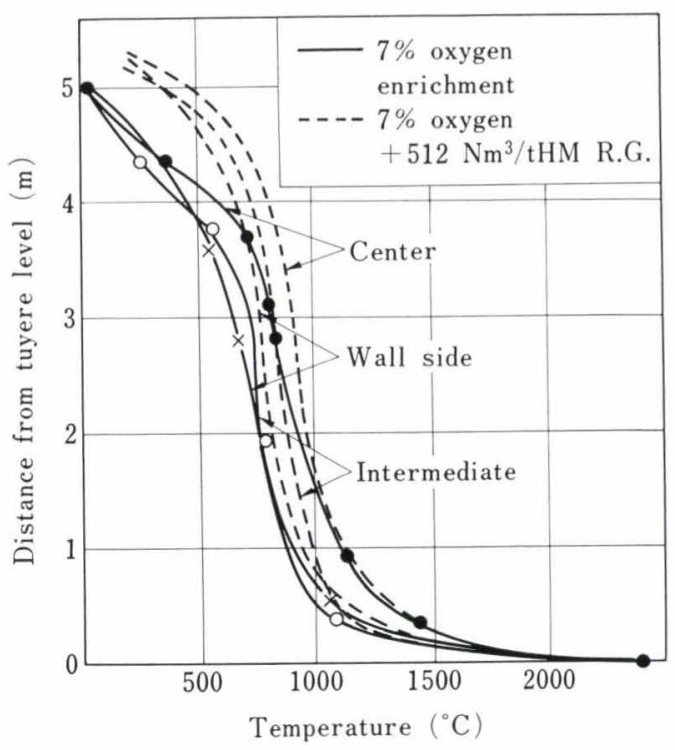

Fig. 17. Temperature profiles of reducing gas injection with and without oxygen enrichment

the contribution came from the decrease in the heat of the solution loss reaction, (6); heat loss, (7); and an increase in the sensible heat of injected gas, (9). When the gas is injected at a $1.5 \mathrm{~m}$ higher level, the decrease in the heat of the solution loss reaction (6) was smaller in spite of the gas injection of $554 \mathrm{Nm}^{3} / \mathrm{tHM}$. In the case of an oxygen enriched gas injection, the decrease in the heat loss had a larger effect.

\section{Improvements of the Temperature Profile in the Furnace}

Excess oxygen enrichment retarded the heat exchange in the upper shaft and increased the amount of direct reduction. Tuyere fuel injection improves these conditions, however, this has a certain limit, described previously. As shown in Fig. 17, when $512 \mathrm{Nm}^{3} / \mathrm{tHM}$ of gas was injected together with $7 \%$ of oxygen enrichment, the temperature stability of the thermal reserve zone could be maintained in spite of low coke rate and high productivity. Thus, the limitations of oxygen enrichment may be overcome by stack gas injection.

Permeability through the furnace melting zone could also be improved by comparing the distance of the calculated points ${ }^{20,22)}$ from the flooding condition (Fig. 18), though these were less successful than a previous operation ${ }^{23)}$ with prereduced pellets.

\section{Conclusions}

(1) When the oxygen enrichment ratio was increased with constant bosh gas volume, the coke rate dropped due to the effect of the decrease in heat loss. However, beyond a certain limit, an increase in direct reduction exceeded the effect of raising the coke rate. This limit in the original experimental furnace $\left(0.63 \mathrm{~m}^{3}\right)$ was at $4 \%$ oxygen enrichment, and it differs in the productivity and coke rate.

(2) The length of thermal reserve zone became shorter and the temperature decreased according to the oxygen enrichment. Beyond $15 \%$ of oxygen en-

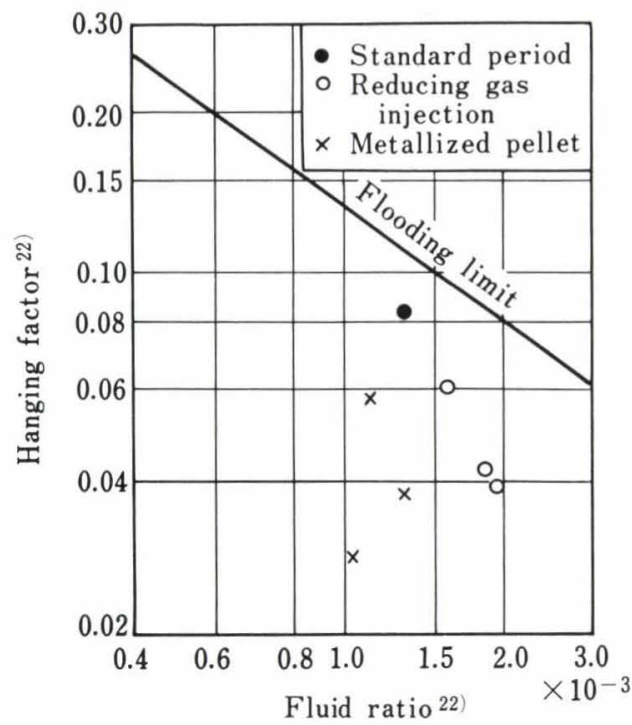

Fig. 18. Advantage of reducing gas injection and prereduced burden for fluid flow at bosh

richment, the reserve zone vanished to reach the limit from the heat exchange in the upper furnace shaft. Those temperature changes caused an increase in direct reduction.

(3) Tuyere fuel injection and the oxygen enrichment can compensate their mutual disadvantages within the limited conditions defined by the lower limit of the flame temperature, the upper limit of the heat content ratio, and the lower limit of the excess oxygen ratio. Even with more than $4 \%$ of oxygen enrichment, about $110 \mathrm{~kg} / \mathrm{tHM}$ of oil injection was considered to be the limit for commercial furnace operation.

(4) In the experimental operation tested in the enlarged furnace $\left(3.2 \mathrm{~m}^{3}\right)$ which was designed to simulate the material and heat balances and the reaction in a commercial furnace, the coke rate was decreased from about $570 \mathrm{~kg} / \mathrm{tHM}$ to $361 \mathrm{~kg} / \mathrm{tHM}$ by $628 \mathrm{Nm}^{3}$ of injected gas produced by the reforming of oil with oxygen. The replacement ratio was 0.75 to 0.82 .

(5) In a reformed gas injection less than 628 $\mathrm{Nm}^{3} / \mathrm{tHM}$, the oxygen of iron oxide removed by direct reduction was decreased from 0.47 to $0.20(\mathrm{O}$ atom $/ \mathrm{Fe}$ atom) and the gaseous reduction by $\left(\mathrm{CO}+\mathrm{H}_{2}\right)$ was increased from 65 to $85 \%$.

(6) Stack gas injection combined with oxygen enrichment cancelled the disadvantages of oxygen enrichment in operating a furnace for high productivity without any increase in the coke rate. Permeability through melting zone was improved.

\section{Acknowledgements}

The authors are grateful to the administratives of Technical Research Center and the member of the Iron Making Sections at Keihin and Fukuyama Works. The authors wish to thank Mr. K. Sano, Mr. T. Fukushima, Mr. K. Endo, and other members who cooperated in the experimental operations. 


\section{REFERENCES}

1) J. Michard and Y. Boudier: Rev. Mét., 17 (1963), No. 6, 513.

2) A. Decker, A. Poos, N. Maieus, R. Balon, and L. Vorman: Blast Furn. Coke Oven \& Raw Mat. Comm. Proc. (1962), 15.

3) E. Ostrowski, G. Kesler, and N. Melcher: J. Metals, 13 (1961), No. 1, 25.

4) G. Suzuki, T. Kobayashi, and T. Miyashita: AIME, Ironmaking Conference Proc., 30 (1971), 503.

5) T. Miyashita and H. Nishio: Tetsu-to-Hagané, 58 (1972), S28.

6) T. Kobayashi, F. Nakatani, K. Okabe, and T. Miyashita: Tetsu-to-Hagané, 56 (1970), 881; Trans. ISIJ, 11 (1971), 417.

7) R. Lavrent: O.P.D. Rept. No. 196/63M, June 1963, 936.

8) N. Melcher, R. Schulter, T. Joseph, and R. Leary: AIME, Ironmaking Conference Proc., 27 (1968), 151.

9) F. Noji, S. Otabe, and K. Omori: Proc. ICSTIS, (1971), 197, Suppl. Trans. ISIJ.

10) A. Decker and A. Poos: Symposium on Blast Furnace Injection, Wollongong (Australia), Feb. 15 and 16, 1972.
11) R. Ando, T. Miyashita, T. Shimotsuma, T. Kaburagi, and Y. Yamada: Nippon Kokan Technical Rep., 54 (1971), 1.

12) Y. Togino, H. Asai, Y. Abe, and A. Hanabusa: Tetsu-toHagané, 51 (1965), 1730.

13) T. Hasegawa, H. Nemoto, E. Sakamoto, and K. Kuroda.: Tetsu-to-Hagané, 51 (1965), 628.

14) T. Miyashita and M. Ohtsuki: Tetsu-to-Hagané, 57 (1971), 2184.

15) H. Beer and H. Krainer: Techn. Mitt. Krupp Forschungsber., 24 (1966), No. 3, 25, BISI Translation 5341, Sept. 1967.

16) P. Reichardt: Arch. Eisenhüttenw., 1 (1927), No. 2, 96.

17) R. Ando, T. Fukushima, and S. Kishimoto: Tetsu-toHagané, 57 (1971), S661.

18) J. Cochery: Rev. Mét., 21 (1967), No. 11, 955.

19) R. Essenhigh: J. Inst. Fuel, 34 (1961), No. 6, 239.

20) T. Miyashita, H. Nishio, T. Shimotsuma, T. Yamada, and M. Ohtsuki: Tetsu-to-Hagané, 58 (1972), 608.

21) A. Rist and G. Bonnivard: Rev. Mét., 19 (1966), 296.

22) Von K. Porthier: Stahl u. Eisen, 90 (1970), No. 5, 240

23) T. Miyashita and M. Ohtsuki: Proc. ICSTIS, (1971), 104, Suppl. Trans. ISIJ. 